Article

\title{
Credit Risk in G20 Nations: A Comparative Analysis in International Finance Using Option-Adjusted-Spreads
}

\author{
Natalia Boliari * and Kudret Topyan (ID
}

check for updates

Citation: Boliari, Natalia, and Kudret Topyan. 2022. Credit Risk in G20 Nations: A Comparative Analysis in International Finance Using Option-Adjusted-Spreads. Journal of Risk and Financial Management 15: 25. https: / /doi.org/10.3390/ jrfm15010025

Academic Editor: Thanasis Stengos

Received: 15 November 2021

Accepted: 28 December 2021

Published: 10 January 2022

Publisher's Note: MDPI stays neutral with regard to jurisdictional claims in published maps and institutional affiliations.

Copyright: (C) 2022 by the authors. Licensee MDPI, Basel, Switzerland. This article is an open access article distributed under the terms and conditions of the Creative Commons Attribution (CC BY) license (https:// creativecommons.org/licenses/by/ $4.0 /)$.
Department of Economics \& Finance, O'Malley School of Business, Manhattan College, Riverdale, NY 10471-4098, USA; kudret.topyan@manhattan.edu

* Correspondence: natalia.boliari@manhattan.edu

\begin{abstract}
Corporate bond yields are the manifestation of the cost of financing for private firms, and if properly evaluated, they provide researchers with valuable risk information. Within this context, this work is the first study producing corporate yield spreads for all S\&P-rated bonds of G20 nations to explain their comparative riskiness. The option-adjusted spread analysis is an advanced method that enables us to compare the bonds with embedded options and different cash flow characteristics. For securities with embedded options, the volatility in the interest rates plays a role in ascertaining whether the option is going to be invoked or not. Therefore, researchers need a spread that, when added to all the forward rates on the tree, will make the theoretical value equal to the market price. The spread that satisfies this condition is called the option-adjusted spread, since it considers the option embedded into the issue. Ultimately, this work investigates the credit risk differentials of S\&P rated outstanding bonds issued by the G20 nations to provide international finance professionals with option-adjusted corporate yield spreads showing the credit risk attributable to debt instruments. Detailed results computed using OAS methodology are presented in tables and used to answer the six vital credit-risk-related questions introduced in the introduction.
\end{abstract}

Keywords: option-adjusted spreads; corporate yield spreads; rating agencies; credit risk; G20 nations

\section{Introduction}

In today's world, the bonds markets around the globe are well integrated. It is not too difficult to obtain the ratings of foreign bonds, purchase foreign bonds, include them in portfolios, or use them for hedging. This paper, therefore, aims to investigate the credit risk differentials of S\&P rated outstanding bonds issued by the G20 countries to provide international finance researchers and practitioners with certain comparison parameters in debt financing. This is valuable for at least two important reasons: first, credit risk standing is important in explaining a country's position in the global financial arena, and second, knowing the credit risk differentials between two countries is a good starting point to assess the country risk that is otherwise hidden inside the credit-risk spread. Along the way, the impacts of country-specific financial inputs on credit risk will also be discussed.

As Cavallo and Valenzuela (2007) highlight, "Corporate bond yields are the manifestation of the cost of financing for private firms. Higher spreads signal that the cost of capital is higher and implies that the profitability of investment opportunities is lower." Fixed income researchers are interested in corporate credit spreads to classify and compare debt instruments in distinct risk classes. Corporate bonds typically trade at higher yields than risk-free government bonds of comparable maturities, partly due to the credit risk of corporate bonds. This difference is frequently referred to as the "credit spread". Lin et al (2020) highlights that the credit spread index and its components have more predictive power for bond returns than conventional default and term spreads. Researchers are lately interested in incorporating environmental and social issues into the assessment of credit risk. Abdul Razak et al. (2020) investigate the relationship between sustainability measures 
and credit risk. Additionally, as underlined by Mutalimov et al. (2021) profitability of investment opportunities are important even at the micro-level for small business. In summary, elaborating on the cost of financing is valuable at multilevel.

In terms of originality, the paper provides option-adjusted spreads (OAS) for all Standard \& Poor rated outstanding corporate bonds for G20 nations, enabling researchers and practitioners to assess the risks and use them as a reference in international bond investment activities. To our knowledge, this is the first paper providing detailed corporate credit spread information at an international scale using the option-adjusted spreads. The use of OAS enables us to compare a variety of bonds without worrying about their embedded options. Analyzing the credit risk spreads for G20 nations is motivated by the fact that G20 has already been defined as an important international forum that brings together the world's major economies, and its members account for more than 80 percent of the world GDP.

Credit risk ${ }^{1}$, however, is one of the factors contributing towards the yield spread among the other contributing factors, such as market depth or liquidity differentials, indirect foreign exchange impacts, optionality or call and conversion features, country risk differentials, and asymmetric tax treatments of corporate and government bonds. Corporate spreads are added to risk-free rates ${ }^{2}$ of government bonds of similar characteristics such as terms and cash flows to obtain the theoretical yield of corporate debt instruments.

Most analysts use the Treasury yield curve as the risk-free reference return, and bondranking companies such as Standard \& Poor or Moody's will provide corporate spreads to obtain the yield of the debt instrument with certain terms ${ }^{3}$. Corporate credit risk has usually been categorized by the rating agencies' conventional abbreviations. If we follow Standard \& Poor's ratings ${ }^{4}$, AAA stands as the highest quality bond with the lowest default risk, followed by other well-known categories.

Credit risk ${ }^{5}$ forecasts the level of risk retained by the borrower and helps bankers to decide on the value of collaterals used. However, it usually includes hard-to-comprehend complexities such as a high-risk borrower with a strong cash flow position, or some factors such as goodwill, bad image, and the financial character that cannot be quantified easily. The desired information on the default position may not be available or may be expensive to obtain. Moreover, the evaluation may be more difficult for start-ups since bankers require a stable business profile with the assured market segment.

Credit risk assessment is also important for lending institutions as it quantifies the chances of non-repayment by the borrower. Rating companies use a variety of information and proprietary formulas and models in computing their rankings and provide information about the loans outstanding of the borrower and the amount and date of payment missed by the borrower in the recent past. The reputation of the company in terms of the frequency of credit cycle used, inventory turnover, and repayment turnover are among the valuable information in quantifying the risk. However, the amount of credit risk cannot assure whether the borrower's position stays the same or changes in the future. Since the default risk is connected to countermeasures such as rate of interest increases and collaterals, projected financial statements with appropriate cash flows will be needed to demonstrate repayment capacity and speed. Solvency ratios such as current ratio, quick ratio, and other ratios such as debt-to-equity, and ROI are commonly used in evaluating credit risk. On the international scale, one may inquire about the dependence structure of countries with significant trade relations. For example, An et al. (2020) shows that US companies are more dependent on exports and imports from China and have lower stock and bond returns. Similarly, as highlighted by Nehrebecka (2021), the probability of default could be organically connected to several unexpected events with strong consequences such as COVID-19.

If properly evaluated and well-understood, option-adjusted credit yield spreads provide researchers with valuable information about credit risk. Motivated by this fact, this paper aims to provide the researchers with a strong tool to obtain and evaluate the riskspreads of corporate bonds regardless of their origin, cash flow characteristics, and option- 
alities. Within this context, this work advocates and uses option-adjusted credit spreads obtained using a one-factor, arbitrage-free binomial tree of normally distributed short-rates for all S\&P rates bonds of G20 nations, regardless of the bonds' embedded options.

The tabulated results are valuable comparison parameters for the participating nations of G20 and used to answer a set of important credit risk-related questions in the context of risk groups, terms, and countries. As such, this paper can be used as a reference for underlined financial questions with domestic and international dimensions.

The six credit risk-relevant questions we attempt to answer are listed below:

(1) Is there a noticeable difference in the credit yield spreads of G20 nations in defined risk classes?

(2) Is there a connection between the yield spread and the country's industrialization level (i.e., developing vs. advanced)?

(3) Is there a correlation between the credit-yield spread and the outstanding bond counts of the country?

(4) Is there a connection between the credit-yield spread and the issue size?

(5) Does the business structure have an impact on credit risk?

(6) Is there a ranking bias initiated by S\&P rankings for US bonds?

Comparable option-adjusted credit spreads for all S\&P rated outstanding bonds of G20 nations will also help us answer those questions and let researchers move forward with more focused follow-ups.

\section{Corporate Yield Spreads}

As briefly covered in the previous section, corporate yield spreads show the credit risk attributable to debt instruments. Comparing the credit yields of debt securities of different countries ranked by recognized ranking agencies provides researchers with valuable information on the country's risk. Within this context, this work is the first study producing corporate yield spreads for S\&P-rated bonds of G20 nations to explain their comparative riskiness.

As Zhou (2020) highlights, traditional corporate bond pricing models have had limited success in explaining actual corporate yield spreads. Studies usually report conflicting results obtained using incomparable models with inconsistent assumptions. Cavallo and Valenzuela (2007) explore the determinants of corporate credit spreads in emerging markets and report that those spreads are determined by firm-specific variables, bond characteristics, macroeconomic conditions, sovereign risk, and global factors. Using a variance decomposition analysis, they show that firm-level characteristics dominate the variance.

Huang and Huang (2012) investigate how much of the corporate yield spread is actually attributable to credit risk. This question can help researchers and practitioners understand how well the corporate bond and equity markets are integrated and also has implications for the theory of capital structure. The authors used the most widely employed framework of credit risk valuation by Black and Scholes (1973) and Merton (1974) to address the question of how credit risk should be priced.

Many studies dealing mostly with medium- and long-maturity bonds have analyzed how much of the observed corporate yield spread can be explained by credit risk, but so far, no consensus has emerged from these studies. Jones et al. (1984) have shown that the credit yield spreads predicted by Merton's (1974) model are significantly below the empirically observed yield spreads. Other studies concluded that credit risk cannot possibly explain the observed corporate yield spreads. Some considerations such as incomplete accounting information (Duffie and Lando 2001) and jumps in asset value (Zhou 2001) are presented as the reasons generating high credit spreads. Anderson and Sundaresan (1996) and Anderson et al. (1996) argue that incorporating strategic default by equity holders can explain why corporate spreads should be high. Mella-Barral and Perraudin (1997) and Collin-Dufresne and Goldstein (2001) argue that firms with good credit quality are likely to issue more debt, leading the spreads comparable to the observed high yield spreads for long-maturity bonds issued by such firms. Longstaff and Schwartz (1995) incorporating bankruptcy 
costs and stochastic interest rates, and Leland $(1994,1998)$ and Leland and Toft (1996) with endogenous default models also show that structural models are capable of generating a large range of credit spreads.

Empirically, recent direct tests of structural models conducted by Anderson and Sundaresan (2000), Lyden and Saraniti (2000), and Eom et al. (2004) show mixed results on structural models explaining the observed corporate yield spreads. Elton et al. (1999) study the spread between corporate spot rates and government bonds. They find that the spread can be explained in terms of compensations for state taxes (since holders of corporate bonds pay state taxes while holders of government bonds do not), and for the additional systematic risk in corporate bond returns relative to government bond returns. Collin-Dufresne et al. (2001) also investigate the determinants of credit spread changes using straight industrial bonds with quoted prices and reported that the variables that should in theory explain credit spread changes, actually, have limited explanatory power. They investigate several macro-economic and financial variables but fail to find a set of variables with explanatory powers. Their results suggest that the corporate bond market is segmented by corporate bond-specific supply/demand shocks.

In more detail, a yield spread is usually considered as the difference between the yield-to-maturity of a particular bond and the yield of a comparable maturity government security. In theory, as noted by Fabozzi $(2006$, p. 340) this is not appropriate, since all cash flows should not be discounted with a single rate but a set of spot rates coming from the yield curve, or forward rates that should be used to discount.

In simple terms, the price of option-free bonds can be calculated by discounting the cash flows using the benchmark rate, however, for securities with embedded options, this is more complicated since the volatility in the interest rates plays a role in ascertaining whether the option is going to be invoked or not. The differences in spread values are mostly attributable to not using the option-adjusted spreads. The use of regular spreads fails to consider the cash flow characteristics of the bonds with embedded options resulting in not directly comparable spreads. Therefore, researchers need a spread that, when added to all the forward rates on the tree, will make the theoretical value equal to the market price. The spread that satisfies this condition is called the option-adjusted spread (OAS), since it considers the option embedded into the issue. As Choudhry (2004) suggests, it is the spread that must be added to the current short-term interest rate to make the "theoretical" price of the corporate bond, as calculated by the pricing model, identical to the observed market price.

In contrast to simple static "yield-curve spread", the OAS quantifies the yield premium using a probabilistic model that incorporates variable interest rates as well as prepayment rates for mortgage-based securities. The difference between option-adjusted and zerovolatility spread provides the implied cost of embedded options in the case of asset-backed security. Binomial and other similar models can be used as alternatives of $\mathrm{OAS}^{6}$, but they require several assumptions to determine the value, making the option-adjusted spread a preferred one.

\section{Group of 20 Nations (G20)}

International finance is a broad term requiring further elaboration of the playing field. In an attempt to stay compact but global, this work uses the group of 20 countries (G20) to add a global dimension to credit ratings and default spreads.

As highlighted in their official web page ${ }^{7}$, the G20 is the international forum that brings together the world's major economies, and its members account for more than 80 percent of world GDP, 75 percent of global trade, and 60 percent of the population of the planet $^{8}$.

G20 has 19 countries and the European Union. In this work, however, we are studying the credit spreads of debt instruments, lowering the count down to 18 counties since Saudi Arabia does not have debt securities. G20 countries are grouped as seen in Table 1 below: 
Table 1. G20 Nations in five groups as of 16 August 2021.

\begin{tabular}{ccccc}
\hline Group 1 & Group 2 & Group 3 & Group 4 & Group 5 \\
\hline Australia & India & Argentina & France & China \\
Canada & Russia & Brazil & Germany & Indonesia \\
Saudi Arabia & South Africa & Mexico & Italy & Japan \\
United States & Turkey & & United Kingdom & South Korea \\
\hline
\end{tabular}

As the table shows, G20 is composed of the world's largest economies, including industrialized and developing nations. Studying G20 will help us observe a good variety of economies with different financial characteristics enabling meaningful comparisons.

\section{The Role of Rating Agencies}

In this study, we are only indirectly interested in the roles of rating agencies, since we primarily focus on the credit spreads comparisons. However, since our classification utilizes S\&P ratings as reference risk classes in our tables, there is a need to cover the rating-agency-related aspects.

The credit rating industry is highly concentrated. The International Organization of Securities Commissions (IOSCO) reports that Moody's, S\&P, and Fitch dominate the credit rating business, with over $94 \%$ of the global market (Smith and Walter 2002). These three agencies are also the dominant players in the U.S. (White 2002).

Rousseau (2009) questions the role of rating agencies during the US subprime crisis of 2007. The paper provides a critical assessment of the regulatory initiatives and addresses the problems that affected the accuracy and the integrity of the rating process. The consensus from the Group of Twenty was that credit rating agencies are essential market participants, and more effective oversight of their activities is necessary.

The paper further highlights that the crisis of 2007 was a wake-up call for the world and several amendments were initiated as a result. The IOSCO has amended its Code of Conduct Fundamentals, the European Parliament has adopted a Proposal by the European Commission for a Regulation on Credit Rating Agencies, the SEC has adopted a final rules amendment dealing with NRSROs, and the Canadian Securities Administrators (CSA) has released Consultation Paper 11-405 that proposes the enactment of a regulatory framework applicable to "approved credit rating organizations".

Today, the world still depends on credit agency ratings in determining the credit risks embedded in credit instruments.

\section{Materials and Methods}

\subsection{Option-Adjusted Spreads and Sector Classification}

Measuring the impact of risk on corporate spreads is not an easy task since it requires comparing the yield spread of government bonds of similar terms and cash flows. However, it is unlikely to find bonds that match well in all dimensions, and it is nearly impossible to determine a definite maturity date for a callable bond due to the optionalities involved. To avoid this problem, in this work, an advanced method, option-adjusted spread analysis, is employed. OAS is essentially a method of making the spreads from different bonds comparable. A simplified computation example is included in Section 5.2. This method enables us to compare bonds with different cash flow characteristics. As underlined by Cavallo and Valenzuela (2007) "It [OAS] simultaneously considers credit risk and contingent cash flow risk, and it is a useful tool for determining an investor's compensation conditional on the structure of the bond".

As we briefly explain in Section 2, OAS helps in the computation of the price of a security with an embedded option, and it is reliable as the base calculation is similar to that of z-spread calculation. Prepayment probability is based on historical data rather than an estimation. It is a bit complex to compute and may be difficult to implement in certain cases, and it also has a few limitations in some portfolio applications, such as the one about 
portfolios 9 . Despite involving complex calculations and placing reliance on sophisticated models, the option-adjusted spread has turned out to be an analytical tool for the evaluation of embedded securities.

As can be seen in Table 2 below, this work uses BCLASS or Bloomberg Barclays Global Sector Classification Scheme for the standardization of the results. The Bloomberg Barclays Global Classification Scheme is a widely accepted standard for investors and uses three pillars to classify the bonds by issuer type. As such, it reflects the large universe of government-related, corporate, and securitized bonds that comprise the global fixedincome investment choice set. In this study, we evaluate only the corporate bonds. Within the corporate bonds class, there are three additional layers: industrial, utility, and financial institutions. Following the conventional approach, financial institutions are not included in the study. Table 2 provides the details of the BCLAAA categories.

Table 2. Bloomberg Barclays Global Sector Classification Scheme.

\begin{tabular}{|c|c|c|c|}
\hline Class 1 & Class 2 & Class 3 & Class 4 \\
\hline \multicolumn{4}{|c|}{ Government-Related } \\
\hline \multirow{12}{*}{ Corporate } & & Basic Industry & Chemicals, metals \& Mining, Paper \\
\hline & & & Aerospace \& Defense, Building Materials, \\
\hline & & Capital Goods & Construction Machinery, Diversified \\
\hline & & & Manufacturing, Environmental, Packaging \\
\hline & Industrial & Communications & $\begin{array}{c}\text { Cable \& Satellite, Media \& Entertainment, } \\
\text { Wireless, Wirelines }\end{array}$ \\
\hline & & & Automotive, Consumer Cyclical Services, Gaming, \\
\hline & & Consumer Cyclical & $\begin{array}{c}\text { Home Construction, Leisure, Lodging, } \\
\text { Restaurants, Retailers }\end{array}$ \\
\hline & & Consumer Non Cyclical & $\begin{array}{c}\text { Consumer Products, Food \& Beverage, Healthcare, } \\
\text { Pharmaceuticals, Supermarkets, Tobacco }\end{array}$ \\
\hline & & Energy & $\begin{array}{l}\text { Independent, Integrated, Midstream, Oil Field } \\
\text { Services, Refining }\end{array}$ \\
\hline & & $\begin{array}{c}\text { Technology } \\
\text { Transportation } \\
\text { Other Industrial }\end{array}$ & Airline, Railroads, Transportation Services \\
\hline & Utility & $\begin{array}{c}\text { Electric } \\
\text { Natural Gas } \\
\text { Other Utility }\end{array}$ & \\
\hline & Financial & & \\
\hline Securitized & & & \\
\hline
\end{tabular}

As Table 2 highlights, the study includes all outstanding corporate bonds of the G20 nations, ranked by Standard $\mathcal{E}$ Poor in industrial \& utility categories represented by the table's unshaded area.

\subsection{Option-Adjusted Spread Analysis: Simplified Computation Algorithm}

Conventional bond price calculations use a constant "yield to maturity" to discount all future cash flows (coupon and principal). However, this is valid only under the assumption of a flat yield curve. When the yield curve has a slope, upward or downward, using constant yield to maturity is incorrect since short-term cash flows and long-term cash flows would require different discount rates. Proper bond valuation requires a benchmark yield curve that captures those rates and provides us with the spot rates that should be used in discounting the distinct cash flows.

For a noncallable bond, the OAS analysis utilizes the "benchmark spot curve" to value a bond by breaking up its cash-flow components and discounting them using the appropriate discount factor. Once the spot rates for the benchmark curve are established, the OAS of a given bond is determined. 
The following steps explain the process of creating a benchmark spot yield curve by Bloomberg Fixed Income Worksheets used for a non-callable bond.

Assuming we have a one-year benchmark bond issued today with two semiannual fixed coupon payments, this bond will provide us with a six-month coupon payment made at month six, and another six-month coupon payment together with the principal at the end of the year.

For illustrative purposes, assume this is a $\$ 1000$ face value $\left(P_{1}=\$ 1000\right) 4$ percent, semiannual coupon bond $\left(C_{1}=C_{2}=\$ 20\right)$ with a current market price of $\$ 1018\left(P_{0}=\$ 1018\right)$. Let's also assume that the six-month spot rate to discount the first coupon payment, $C_{1}=$ $\$ 20$, is 2 percent $\left(R_{S 1}=0.02\right.$ semiannual).

Using this information, we can compute the one-year spot rate using the following relationship:

$$
\left[P_{0}-\left(\frac{C_{1}}{1+\frac{R_{s 1}}{2}}\right)\right]\left(1+\frac{R_{s 2}}{2}\right)^{2}=\left(P_{1}+C_{2}\right)
$$

Substituting the given information yields

$$
\left[\$ 1018-\left(\frac{\$ 20}{1.02}\right)\right]\left(1+\frac{R_{s 2}}{2}\right)^{2}=\$ 1020
$$

Solving for $R_{\mathrm{S} 2}$ yields $R_{\mathrm{S} 2}=0.010764$ or 1.010764 percent as the one-year spot rate used to discount the cash flows made at the end of the year, at point 1.

In other words, the following equality holds using two different spot rates; $2 \%$ for the six-month spot rate, and $1.0764 \%$ for the one-year spot rate ${ }^{10}$.

$$
\$ 1018=\frac{\$ 20}{1.02}+\frac{\$ 1020}{1.010764^{2}}
$$

In other words, the six-month coupon payment of the one-year benchmark issue is discounted to using the six-month spot rate, and the amount is subtracted from the current market price to solve for the one-year spot rate.

For longer-term bonds, the spot rates for successive terms are solved the same way, generating a spot curve based on the underlying benchmark yield curve resulting in a series of discount factors unique to each term of a bond's cash flows.

Thus, rather than simply comparing a bond's yield to maturity to a benchmark issue, OAS measures the constant spread that must be added to the current short-term interest rate to make the price of the risk-free bond, as calculated by the pricing model, identical to the observed market price of the corporate bond.

For the OAS spread analysis for callable bonds with an unknown maturity date, Bloomberg uses a one-factor, arbitrage-free binomial tree of normally distributed shortrates in order to establish a distribution of several different interest rate scenarios driven by the volatility input for the interest rate and examines the bond's call schedule to establish the evolution of rates over time. Once these cash flows are modeled, the present value of the callable bond is determined by using the discount rates obtained from the tree, together with an OAS.

\section{Tabulated Results}

This section presents the computed option-adjusted yield spreads for all outstanding bonds of the G20 nations rated by Standard and Poor using S\&P risk classes matching the terms of Treasuries. The OAS values in those tables are important, as they represent the relative riskiness of bonds for the included nations for a given risk class, and they constitute the cost of financing for private firms. Observed spread differences within a risk group, such as BBB, imply the country risk, market depth, and liquidity differentials.

The data used in this work was obtained from Bloomberg on 16 August 2021. OAS values are computed using Bloomberg's built-in OAS function. Bloomberg uses a one-factor, 
arbitrage-free binomial tree of normally distributed short-rates. Using those rates creates a distribution of several different interest rate scenarios driven by the volatility and examines the bond's call schedule to establish the evolution of rates over time. Once the cash flows obtained are modeled, the present value of the callable bond can be determined by using the discount rates obtained from the tree, together with an OAS.

The results can be used in three different ways: first to obtain the cost of financing and therefore the riskiness in a target G20 nation, and secondly, to observe the characteristics of terms to maturity differences within and between the risk classes for a target G20 nation. These are displayed in Tables 3-7. Finally, the spreads will let us compare the G20 countries' risk structure for target risk classes and this is done in Table 8. In addition, the results are used to answer our six reference questions presented in the introduction section.

The main part of Tables 3-7 provides group-specific yield spreads for the five G20 groups, including additional supporting financial information such as the number of outstanding bonds and their distribution for terms and credit ratings. As an example, if we look at the first listed G20 nation, Australia, in Table 3, we see that there are 172 outstanding bonds rated by S\&P, and of those 172, we have only $2 \mathrm{AA}+$ rated bonds, while we have $45 \mathrm{BBB}$ rated bonds. When we evaluate the terms of those 172 bonds, we see that Australia has 18 short-term bonds with less than one year term and 32 bonds with terms 7 to 10 years. Vertical (count) and horizontal (terms) summations of those numbers will add up to the total number of bonds outstanding (172).

Inside Table 3, we observe the computed option-adjusted spreads. Australia has 6 A-rated bonds with less than one year term with 11 basis points OAS value. This means the group of 6 A-rated bonds require 11 basis points option-adjusted credit spread over the risk-free rate. If we move to A-rated 20-30 year bonds, the OAS is 115 basis points or 1.15 percent over the risk-free rate.

All tables provide the OAS valued computed on 16 August 2021 with the corresponding US Treasury rates with 6 months, 1, 2, 3, 5, 7, 10, 20, and 30 years corresponding to $0.05,0.08,0.21,0.42,0.75,1.04,1.26,1.82$, and 1.92, respectively. As an illustrative example, a 30-year Australian bond's OAS of 115 basis points, or 1.15 percent, must be added to the corresponding 30-year treasury rate of 1.92 percent, making the total yield equal to 3.07 percent.

A vertical evaluation of the table provides us with additional information. For instance, Australia has 29 outstanding bonds in the 5-7 years range. The last number in this column, 369 , shows that the $\mathrm{B}+$ rated bonds in this risk class will require 369 basis points or a 3.69 percent default spread in addition to the risk-free rate of the same term treasury bonds (5 years) that is equal to 0.75 percent. If we add up bond numbers vertically, we obtain the total number of bonds outstanding for the nation showing on top. For Australia, the total number of bonds outstanding is 172 . This information is used to answer question \#3: the correlation between the credit-yield spread and the outstanding bond counts of the country.

A dash in the box means that either there is no outstanding bond with such rating or with this term for the G20 nation in question. Australia's computed OAS values show how the riskiness of those bonds are distributed for the terms and ratings. The highest spread in the table is 7.17 percent for 3-5 year B-rated bonds.

The secondary boxes appearing at the top right of Tables 3-7 have two panels. The left panel shows the issue amount of the nation in three categories: less than $\$ 500$ million, \$500 to $\$ 1$ billion, and over $\$ 1$ billion. For Australia, there are 172 bonds, and 108 of them have the issue amount less than $\$ 500$ million, 56 of them are between $\$ 500$ million to $\$ 1$ billion, and only 8 of them have an issue value of over $\$ 1$ billion. This information is used to answer question \#4: If the credit-yield spread and the size of the issues are related?

The right panel of the little box reports the business structure of the issuers: Again, out of 172 bonds, 137 are coming from operating companies (OPCO) while 35 are coming from holding companies (HOLDCO). For the sake of definitional clarity, a holding company is a parent business entity that doesn't manufacture anything, sell any products or services, 
or conduct any other business operations, but, as the name implies, holds membership interests in other companies. OPCO is the abbreviation for "operating company", typically used when describing the primary operating company which might be owned by a subsidiary. Regardless of the structure used, a HOLDCO financing is a loan made at the holding company level and such a loan may be secured by assets or revenues of the subsidiaries and operating companies. This information, is used to answer question \#5: does the business structure have an impact on credit risk?

Table 3 summarizes the G20-Group 1. These are all industrialized countries with developed financial markets. (Note again that Saudi Arabia does not have debt instruments and is not included in this study). The US dominates the bond counts with 11,470 outstanding bonds and also is the only country with AAA-rated bonds outstanding. The US is followed by Canada with 993 bonds outstanding and the highest-rated bonds are the $\mathrm{AA}+$ ones. Australia is the last in this group in terms of the number of bonds outstanding with 172 bonds.

Table 4, below, reports the corporate spreads for India, Russia, South Africa, and Turkey. The differences in S\&P-rated bond counts are remarkable. In Group 2, India has the highest count with 83 bonds, followed by Turkey with 28 bonds. Russia and South Africa are the third and fourth with 11 and 8 rated bonds, respectively. It is hard to obtain within-group credit risk comparisons from the table as it lacks visible regularities. However, the term differences in the bonds issued by those countries are easily noticeable: Turkey would not issue bonds with over 7-year terms, and Russia would not issue bonds with over 3-year terms, however, India issues bonds with all possible terms up to $30+$ years and is the only country in this group with the $\mathrm{BBB}+$ rating.

Table 5 below, G20-Group 3 reports the results of three Latin American countries, Argentina, Brazil, and Mexico. The market in this group is more viable than the Group 2 countries. Mexico stands out as the country with the highest bond count of 183 . Mexico is also the only country with an A- rating.

Table 6 covers the European members of the G20: France, Germany, Italy, and the UK. As Table 6 shows, France and the UK present similar characteristics with both having AA as the highest rakings. All four countries have well-developed financial markets and strong industrial economies. Group 4 is the second most advanced group in G20 in terms of bond count: the UK tops the list with 713 outstanding bonds followed by France with 639 bonds, Germany follows with 477, and Italy is the last with 241 bonds.

The UK has slightly higher corporate spreads than France, implying higher credit risk in the same term and risk class instruments. The difference may be attributable to liquidity differences and country risk differentials. Readers should compare the tables for specific terms by moving vertically and checking similar risk classes for the term chosen. Alternatively, Table 8 in the next section may provide a simple direct comparison.

Table 7 below presents the corporate yield spreads for the far-east nations of G20Group 5: China, Indonesia, Japan, and South Korea. In this group, Japan stands out with 309 rated bonds outstanding followed by China with 128 bonds, South Korea is third with 72 bonds, and Indonesia is the last with only 5 rated bonds outstanding.

One important distinction of Table 7 is the high corporate credit spreads associated with Chinese bonds. The difference is significant, consistent, and the reflection of the high country risk rather than liquidity risk. For example, a BBB bond with a 5-year term has a spread of 70 basis points for South Korea, 41 basis points for Japan, but 214 basis points for China. Table 7 also highlights that Indonesia and South Korea have shorter terms compared to Japan and China with a maximum term of 7 years for China and 20 years for South Korea. 
Table 3. G20-Group 1-Corporate credit spreads with S\&P ratings and terms to maturity, issue amount, and the business structure of the issuer. Adding those spreads to the corresponding risk-free rate provides the expected return of the bonds. (Date: 16 August 2021).

\begin{tabular}{|c|c|c|c|c|c|c|c|c|c|c|c|c|c|c|c|}
\hline GROUP 1 & Count & Term & $\leq 1$ & $1-2$ & $2-3$ & $3-5$ & $5-7$ & $7-10$ & $10-20$ & $20-30$ & $30+$ & & & & \\
\hline \multirow[t]{14}{*}{ AUSTRALIA } & 172 & Rating & 18 & 16 & 20 & 29 & 32 & 32 & 12 & 9 & 4 & $\leq 500 \mathrm{~mm}$ & 108 & OPCO & 137 \\
\hline & 2 & $\mathrm{AA}+$ & - & - & - & - & - & 77 & - & 83 & - & $500 \mathrm{M}$ TO 1 B & 56 & HOLDCO & 35 \\
\hline & 7 & AA & - & - & 76 & 97 & 66 & 66 & 0 & - & - & $>1 \mathrm{~B}$ & 8 & & \\
\hline & 1 & AA- & - & 0 & - & - & - & - & - & - & - & & & & \\
\hline & 17 & $\mathrm{~A}+$ & 14 & 26 & 31 & 19 & 26 & - & - & - & - & & & & \\
\hline & 6 & A & 11 & - & 10 & 43 & - & - & - & 115 & - & & & & \\
\hline & 52 & A- & 17 & 20 & 41 & 53 & 72 & 69 & 80 & 61 & - & & & & \\
\hline & 22 & BBB+ & - & 49 & 75 & 68 & 116 & 148 & - & - & - & & & & \\
\hline & 45 & BBB & - & 63 & 73 & 88 & 123 & 145 & 118 & 178 & 90 & & & & \\
\hline & 8 & BBB-- & - & 140 & 91 & 165 & 215 & 215 & - & - & - & & & & \\
\hline & 6 & BB+ & - & - & 156 & - & 185 & 204 & - & - & - & & & & \\
\hline & 2 & BB- & - & 786 & - & - & - & - & - & - & - & & & & \\
\hline & 2 & $\mathrm{~B}+$ & - & - & - & - & 369 & - & - & - & - & & & & \\
\hline & 2 & $\mathrm{~B}$ & - & - & - & 717 & - & - & - & - & - & & & & \\
\hline \multirow[t]{18}{*}{ CANADA } & 993 & & 41 & 66 & 63 & 146 & 137 & 114 & 168 & 205 & 53 & $\leq 500 \mathrm{~mm}$ & 727 & OPCO & 773 \\
\hline & 9 & AA+ & - & - & - & - & - & 83 & 87 & 100 & 96 & $500 \mathrm{M}$ TO $1 \mathrm{~B}$ & 229 & HOLDCO & 220 \\
\hline & 7 & AA & - & - & - & - & - & - & - & 103 & 102 & $>1 \mathrm{~B}$ & 37 & & \\
\hline & 18 & AA- & - & - & - & - & 23 & 40 & 92 & 89 & 161 & & & & \\
\hline & 44 & A+ & -3 & 6 & 10 & 18 & 41 & 55 & 98 & 101 & 96 & & & & \\
\hline & 69 & A & 4 & 23 & 3 & 18 & 47 & 67 & 120 & 121 & 123 & & & & \\
\hline & 144 & BBB & 28 & 45 & 49 & 93 & 81 & 97 & 173 & 184 & 222 & & & & \\
\hline & 117 & BBB- & 36 & 52 & 50 & 79 & 94 & 124 & 207 & 226 & 288 & & & & \\
\hline & 30 & BB+ & - & 142 & 149 & 53 & 213 & 224 & 217 & - & 252 & & & & \\
\hline & 40 & BB & - & - & 644 & 207 & 248 & 272 & - & 355 & 358 & & & & \\
\hline & 23 & BB- & - & 103 & - & 345 & 325 & 330 & - & - & - & & & & \\
\hline & 12 & $\mathrm{~B}+$ & - & - & 525 & 432 & 825 & 358 & - & - & - & & & & \\
\hline & 26 & B & - & 635 & - & 454 & 474 & 447 & - & - & - & & & & \\
\hline & 18 & B- & - & 1103 & 819 & 526 & 292 & 300 & - & - & - & & & & \\
\hline & 23 & CCC + & - & 202 & - & 499 & 548 & 536 & - & - & - & & & & \\
\hline & 5 & CCC & - & - & - & 665 & - & - & - & - & - & & & & \\
\hline & 2 & $\mathrm{CCC}-$ & - & - & - & - & - & - & 449 & - & - & & & & \\
\hline & 2 & CC & - & - & - & - & - & - & - & - & - & & & & \\
\hline
\end{tabular}


Table 3. Cont.

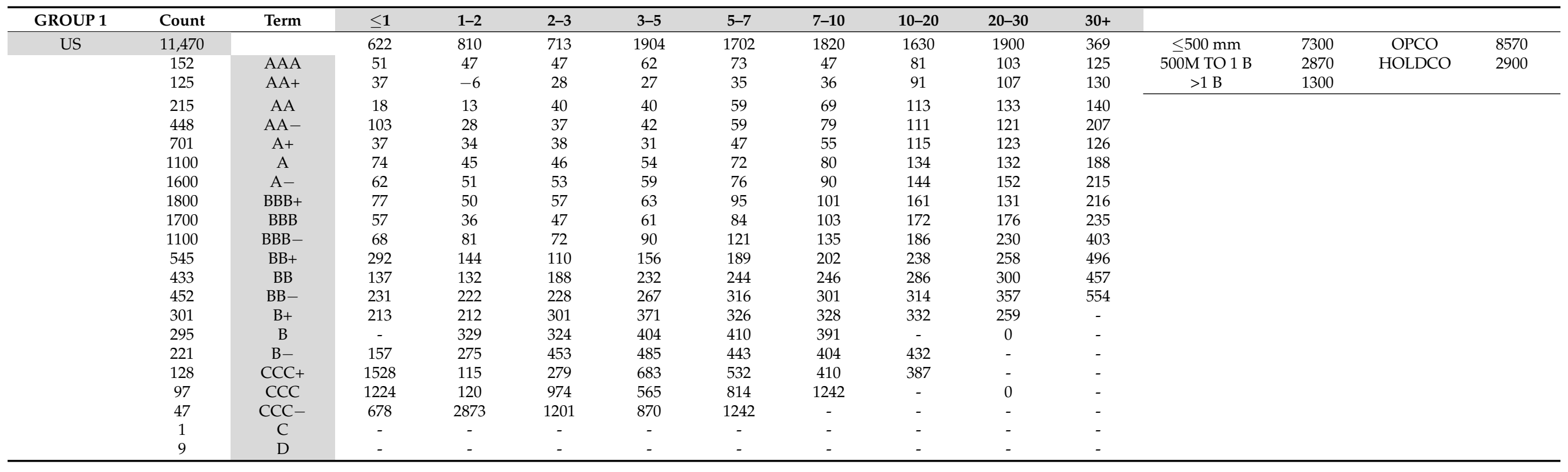


Table 4. G20-Group 2-Corporate credit spreads with S\&P ratings and terms to maturity, issue amount, and the business structure of the issuer. Adding the spreads to the corresponding risk-free rate provides the expected return of the bonds. (Date: 16 August 2021).

\begin{tabular}{|c|c|c|c|c|c|c|c|c|c|c|c|c|c|c|c|}
\hline GROUP 2 & Count & Term & $\leq 1$ & $1-2$ & $2-3$ & $3-5$ & $5-7$ & 7-10 & $10-20$ & $20-30$ & $30+$ & & & & \\
\hline \multirow[t]{7}{*}{ INDIA } & 83 & Rating & 5 & 6 & 10 & 12 & 16 & 14 & 9 & 4 & 7 & $\leq 500 \mathrm{~mm}$ & 51 & OPCO & 47 \\
\hline & 19 & $\mathrm{BBB}+$ & 67 & - & - & 111 & 103 & - & 180 & 217 & 0 & $500 \mathrm{M}$ TO $1 \mathrm{~B}$ & 30 & HOLDCO & 36 \\
\hline & 34 & BBB- & - & 127 & 129 & 163 & 215 & 227 & 266 & - & - & $>1 \mathrm{~B}$ & 2 & & \\
\hline & 8 & BB- & - & 278 & 376 & - & 343 & - & - & - & - & & & & \\
\hline & 3 & B & - & - & 362 & 354 & - & - & - & - & - & & & & \\
\hline & 11 & B- & 635 & 1000 & 1186 & - & 527 & 545 & - & - & - & & & & \\
\hline & 2 & $\mathrm{CCC}-$ & - & - & - & 0 & - & - & - & - & - & & & & \\
\hline \multirow{3}{*}{ RUSSIA } & 2 & $\mathrm{BBB}-$ & -41 & - & - & - & - & - & - & - & - & $500 \mathrm{M}$ TO $1 \mathrm{~B}$ & 5 & HOLDCO & 5 \\
\hline & 8 & $\mathrm{BB}+$ & -89 & 161 & 159 & - & - & - & - & - & - & $>1 \mathrm{~B}$ & 2 & & \\
\hline & 1 & $\mathrm{~B}+$ & - & - & 647 & - & - & - & - & - & - & & & & \\
\hline \multirow[t]{2}{*}{$\begin{array}{l}\text { SOUTH } \\
\text { AFRICA }\end{array}$} & 8 & & & & & 4 & 2 & 2 & & & & $\leq 500 \mathrm{~mm}$ & 8 & $\mathrm{OPCO}$ & 2 \\
\hline & 8 & $\mathrm{BB}-$ & - & - & - & 396 & 358 & - & 476 & - & - & $500 \mathrm{M}$ TO 1 B & - & HOLDCO & 6 \\
\hline \multirow[t]{5}{*}{ TURKEY } & 28 & & 1 & 6 & 4 & 11 & 6 & & & & & $\leq 500 \mathrm{~mm}$ & 18 & OPCO & 12 \\
\hline & 4 & $\mathrm{BB}+$ & 167 & 240 & - & 309 & - & - & - & - & - & & & & \\
\hline & 16 & BB- & - & 252 & 280 & 295 & 342 & - & - & - & - & & & & \\
\hline & 2 & $\mathrm{~B}+$ & - & - & - & 408 & - & - & - & - & - & & & & \\
\hline & 2 & B & - & - & - & - & 697 & - & - & - & - & & & & \\
\hline
\end{tabular}


Table 5. G20-Group 3-Corporate credit spreads with S\&P ratings and terms to maturity, issue amount, and the business structure of the issuer. Adding the spreads to the corresponding risk-free rate provides the expected return of the bonds. (Date: 16 August 2021).

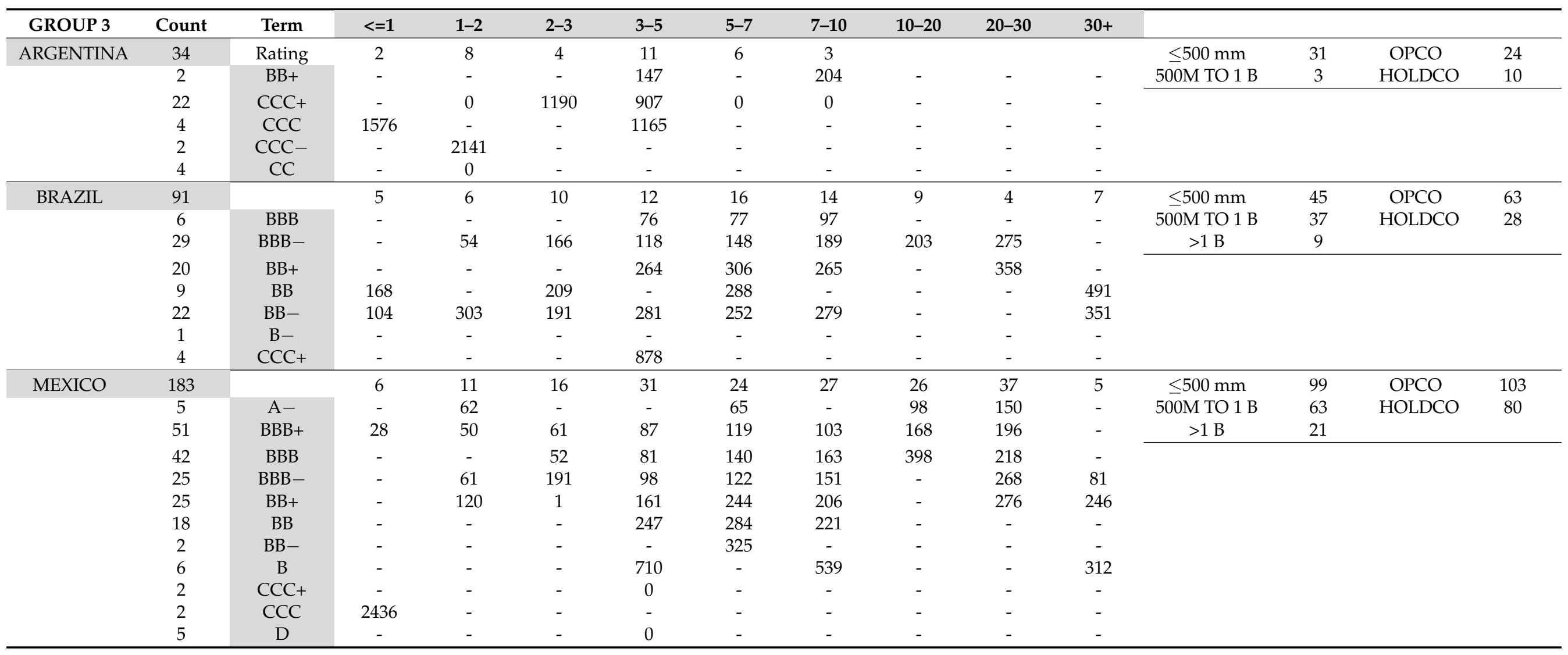


Table 6. G20-Group 4-Corporate credit spreads with S\&P ratings and terms to maturity, issue amount, and the business structure of the issuer. Adding the spreads to the corresponding risk-free rate provides the expected return of the bonds. (Date: 16 August 2021).

\begin{tabular}{|c|c|c|c|c|c|c|c|c|c|c|c|c|c|c|c|}
\hline GROUP 4 & Count & Term & $\leq 1$ & $1-2$ & $2-3$ & $3-5$ & $5-7$ & $7-10$ & 10-20 & $20-30$ & $30+$ & & & & \\
\hline \multirow[t]{14}{*}{ FRANCE } & 639 & Rating & 57 & 55 & 70 & 152 & 119 & 88 & 52 & 14 & 32 & $\leq 500 \mathrm{~mm}$ & 285 & OPCO & 389 \\
\hline & 20 & AA & 18 & 2 & 4 & 5 & 16 & 14 & 17 & - & - & $500 \mathrm{M}$ TO 1 B & 289 & HOLDCO & 250 \\
\hline & 17 & $\mathrm{~A}+$ & 8 & 8 & 22 & 25 & 10 & 11 & 98 & 135 & - & $>1 \mathrm{~B}$ & 65 & & \\
\hline & 81 & $\mathrm{~A}-$ & 11 & 14 & 25 & 26 & 25 & 26 & 32 & 0 & - & & & & \\
\hline & 157 & $\mathrm{BBB}+$ & 37 & 18 & 26 & 30 & 28 & 53 & 64 & 122 & 145 & & & & \\
\hline & 74 & BBB & 16 & 25 & 33 & 26 & 38 & 47 & 88 & - & - & & & & \\
\hline & 73 & $\mathrm{BBB}-$ & 30 & 33 & 46 & 49 & 69 & 85 & 146 & - & 111 & & & & \\
\hline & 17 & BB & - & - & - & 203 & 210 & - & - & - & - & & & & \\
\hline & 12 & BB- & - & - & - & - & - & - & - & - & - & & & & \\
\hline & 25 & $\mathrm{~B}+$ & 187 & 330 & 321 & 400 & 358 & - & - & - & 319 & & & & \\
\hline & 47 & B & 294 & 302 & 501 & 340 & 362 & 406 & - & - & - & & & & \\
\hline & 17 & B- & - & 1128 & 1470 & 524 & 414 & - & - & - & - & & & & \\
\hline & 14 & $\mathrm{CCC}+$ & - & - & - & - & - & - & - & - & - & & & & \\
\hline & 4 & $\mathrm{CCC}$ & - & 740 & - & - & - & - & - & - & 468 & & & & \\
\hline \multirow[t]{15}{*}{ GERMANY } & 477 & & 79 & 60 & 65 & 93 & 75 & 54 & 30 & 5 & 16 & $\leq 500 \mathrm{~mm}$ & 257 & OPCO & 342 \\
\hline & 3 & $\mathrm{~A}+$ & - & - & - & 13 & - & 14 & 30 & - & - & $500 \mathrm{M}$ TO 1 B & 172 & HOLDCO & 135 \\
\hline & 60 & $\mathrm{~A}-$ & 32 & 25 & 39 & 40 & 33 & 45 & 50 & - & - & & & & \\
\hline & 70 & $\mathrm{BBB}+$ & 38 & 38 & 41 & 45 & - & 52 & 45 & - & 110 & & & & \\
\hline & 96 & BBB & 30 & 18 & 25 & 29 & 51 & 53 & 75 & 166 & - & & & & \\
\hline & 34 & BBB- & 151 & 35 & 45 & 50 & 184 & 70 & 87 & - & 93 & & & & \\
\hline & 17 & $\mathrm{BB}+$ & 56 & - & 83 & 124 & 175 & 202 & - & - & 183 & & & & \\
\hline & 6 & BB & - & - & 0 & - & 186 & - & - & - & 186 & & & & \\
\hline & 24 & BB- & - & - & 236 & 262 & 240 & 340 & - & - & - & & & & \\
\hline & 11 & $\mathrm{~B}+$ & - & - & 482 & 313 & 269 & 371 & - & - & 0 & & & & \\
\hline & 18 & B & 89 & 123 & 171 & 407 & 367 & - & - & - & - & & & & \\
\hline & 11 & B- & - & 125 & 618 & 395 & - & - & - & - & - & & & & \\
\hline & 10 & $\mathrm{CCC}+$ & - & 1366 & - & 398 & 461 & - & - & - & 0 & & & & \\
\hline & 1 & CCC & - & - & - & - & - & - & - & - & - & & & & \\
\hline & & $\mathrm{CC}$ & - & - & - & - & - & - & - & - & - & & & & \\
\hline
\end{tabular}


Table 6. Cont.

\begin{tabular}{|c|c|c|c|c|c|c|c|c|c|c|c|c|c|c|c|}
\hline GROUP 4 & Count & Term & $\leq 1$ & $1-2$ & $2-3$ & $3-5$ & $5-7$ & $7-10$ & $10-20$ & $20-30$ & $30+$ & & & & \\
\hline \multirow[t]{11}{*}{ ITALY } & 241 & & 18 & 17 & 26 & 54 & 43 & 34 & 33 & 2 & 14 & $\leq 500 \mathrm{~mm}$ & 92 & OPCO & 157 \\
\hline & 34 & $\mathrm{~A}-$ & 10 & 13 & 57 & 29 & 68 & 82 & 153 & - & - & $500 \mathrm{M}$ TO 1 B & 114 & HOLDCO & 84 \\
\hline & 85 & $\mathrm{BBB}+$ & 59 & 7 & 17 & 31 & 56 & 67 & 116 & 167 & - & $>1 \mathrm{~B}$ & 35 & & \\
\hline & 21 & BBB & 25 & 29 & 34 & 40 & 50 & 68 & 283 & - & 216 & & & & \\
\hline & 12 & BBB- & - & - & - & - & 83 & 105 & - & - & 120 & & & & \\
\hline & 36 & $\mathrm{BB}+$ & 54 & 79 & 108 & 149 & 137 & 172 & 320 & - & 377 & & & & \\
\hline & 15 & $\mathrm{BB}$ & 93 & 102 & 87 & 119 & 146 & 154 & 292 & - & - & & & & \\
\hline & 6 & BB- & - & - & - & 203 & 310 & 235 & - & - & - & & & & \\
\hline & 20 & B & - & 282 & - & 383 & 405 & - & - & - & - & & & & \\
\hline & 8 & $\mathrm{~B}-$ & - & - & 443 & 611 & 583 & - & - & - & - & & & & \\
\hline & 2 & CCC & - & - & - & 495 & - & - & - & - & - & & & & \\
\hline
\end{tabular}

Table 7. G20-Group 5-Corporate credit spreads with S\&P ratings and terms to maturity, issue amount, and the business structure of the issuer. Adding the spreads to the corresponding risk-free rate provides the expected return of the bonds. (Date: 16 August 2021).

\begin{tabular}{|c|c|c|c|c|c|c|c|c|c|c|c|c|c|c|c|}
\hline GROUP 5 & Count & Term & $\leq 1$ & $1-2$ & $2-3$ & $3-5$ & $5-7$ & $7-10$ & 10-20 & $20-30$ & $30+$ & & & & \\
\hline \multirow[t]{10}{*}{ CHINA } & 128 & Rating & 13 & 14 & 13 & 25 & 8 & 22 & 13 & 13 & 7 & $\leq 500 \mathrm{~mm}$ & 54 & OPCO & 18 \\
\hline & 54 & $\mathrm{~A}+$ & 42 & 55 & 61 & 56 & 102 & 117 & 159 & 173 & 185 & $500 \mathrm{M}$ TO 1 B & 47 & HOLDCO & 110 \\
\hline & 2 & A & - & - & - & 105 & - & 124 & - & - & - & $>1 \mathrm{~B}$ & 27 & & \\
\hline & 15 & BBB & 157 & - & 224 & 214 & 383 & 150 & - & - & 174 & & & & \\
\hline & 31 & BBB-- & 176 & 146 & 112 & 156 & 125 & 186 & 194 & 268 & - & & & & \\
\hline & 2 & $\mathrm{BB}+$ & 362 & - & - & 380 & - & - & - & - & - & & & & \\
\hline & 8 & $\mathrm{BB}$ & 147 & 334 & - & 351 & - & - & - & - & - & & & & \\
\hline & 3 & $\mathrm{~B}+$ & 1768 & 1706 & 478 & - & - & - & - & - & - & & & & \\
\hline & 3 & B & 1057 & 540 & - & 634 & - & - & - & - & - & & & & \\
\hline & 2 & B- & 577 & - & 759 & - & - & - & - & - & - & & & & \\
\hline
\end{tabular}


Table 7. Cont.

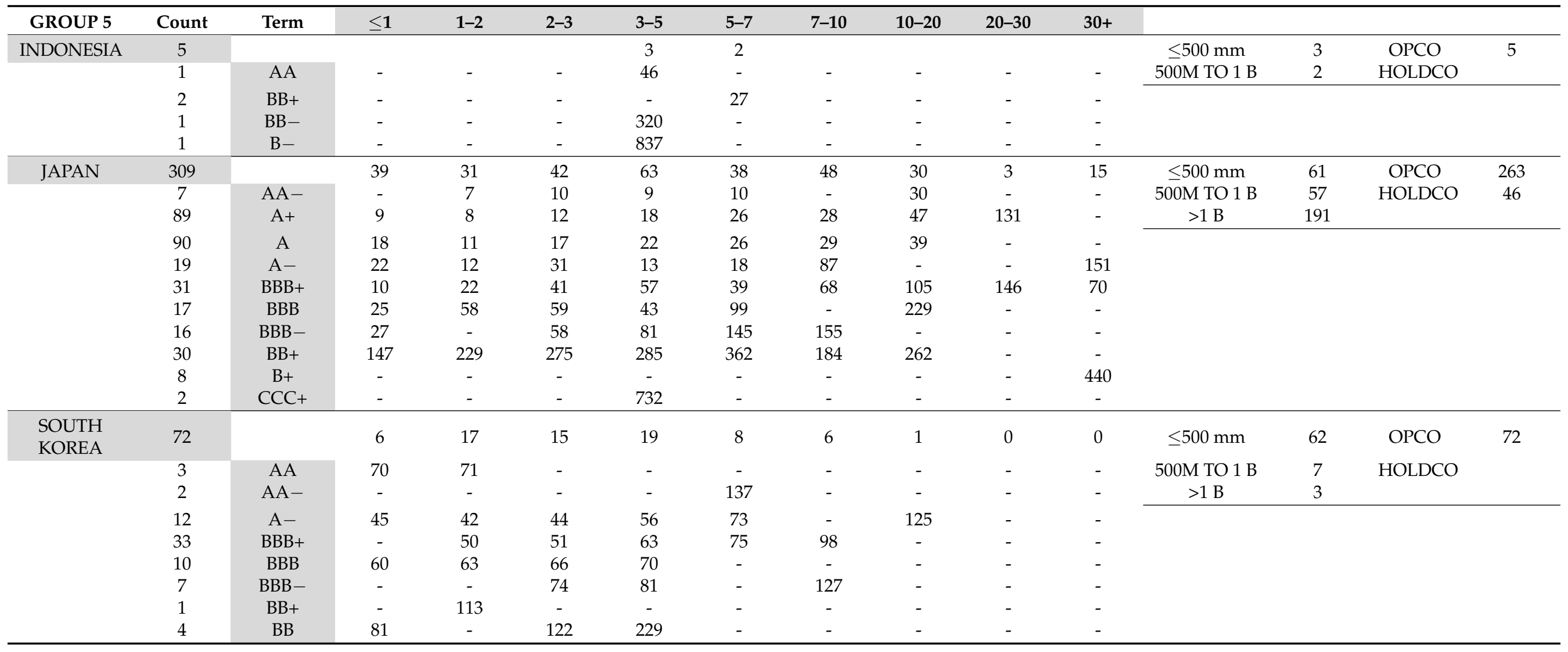


Table 8. The credit spreads in descending order. Each section's first entry is the nation with the highest number of such bonds outstanding. Spreads are in basis points. No spread if it cannot be computed or no such bonds outstanding for the set term. (Date: 16 August 2021).

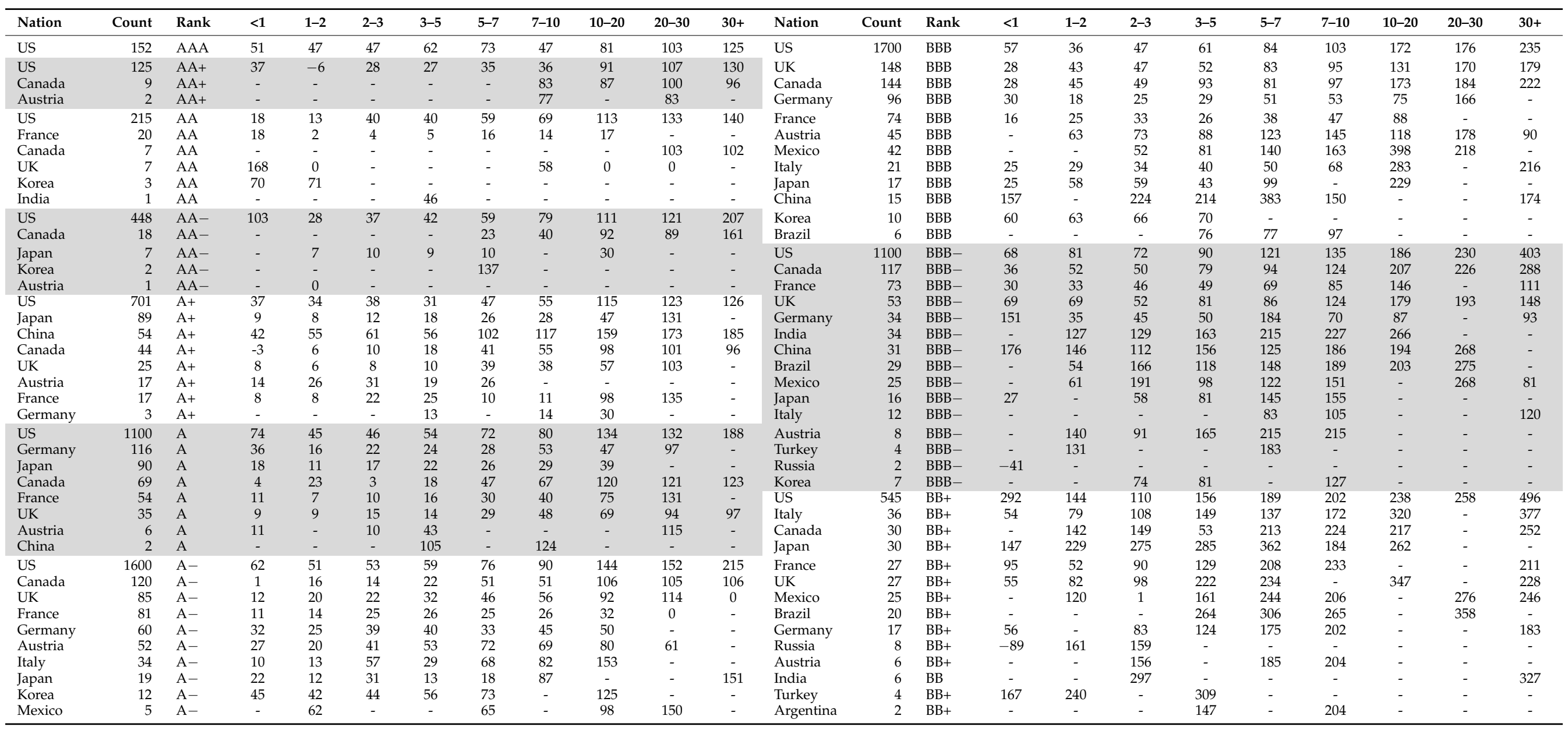


Table 8. Cont.

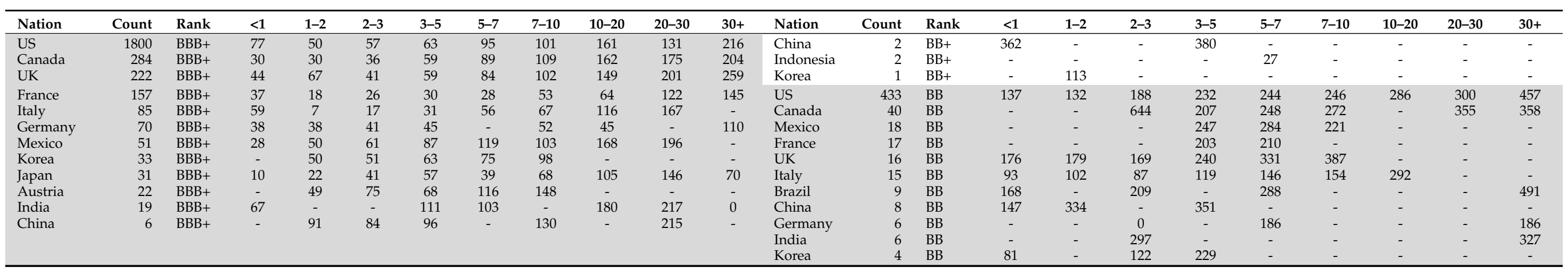


Table 8 provides us with directly comparable corporate yield spreads by risk classes. The table lists all S\&P rated bonds of G20 nations for risk classes from AAA to BB. For instance, in S\&P A-rated bonds group, there are 1100 U.S. bonds, followed by Germany with 116 bonds. The group has China as the last one with only 2 A-rated bonds. If one compares, say, bonds with 5-year terms, the corporate credit spread for the US is 54 basis points, but it is only 24 basis points for Germany, 14 basis points for the UK, 43 basis points for Australia, and 105 basis points for China. This information is extremely valuable for international bond traders as it standardizes the bonds' terms and risk class for direct comparison.

Table 8 displays several important risk-related observations and helps us answer question \#6: do we have a ranking company-induced ranking bias favoring the US bonds? As it can be seen in Tables 3 and 8, US bonds' credit spreads are significantly higher than the other participating nations' bonds in any given risk category with just a few exceptions. This is much more visible in the industrialized nations, as US bonds are systematically riskier in all risk categories within the industrialized countries. When all countries are included, China stands out as the riskiest country from the credit-risk standpoint.

We observe from the table that the US is the only country with AAA-rated bonds. Interestingly, those AAA US bonds have higher credit-yield spreads than AA+ bonds, and this is possibly due to the illiquidity of the AAA bonds.

An important observation is the impact of bond counts. In any risk class from AAA to $\mathrm{BB}$, the US has a higher number of bonds outstanding than the total number of all other G20 nations bond counts. This is in line with the fact that the US accounts for about 40 percent of the world's financial markets.

Another notable observation is that the US has the highest credit spread in almost every risk class from $\mathrm{AAA}$ to $\mathrm{BB}$ within the industrial nations. This is important, since it shows the fairness of the rating agency in treating US bonds and foreign bonds in the same risk class.

Table 9 below presents information about business structures and their relative importance. Operating companies are the primary entities while holding companies do not conduct any business operations but hold membership interests in other companies. The number of operating and holding companies is parallel to the size of the nations' financial markets. The US has 8570 operating companies and 2900 holding companies while Russia has 6 operating and 5 holding companies. Except for two G20 nations, South Korea and Indonesia, all nations have holding companies. In this work, we are interested in not the number of holding companies a nation has, but the ratio of operating to holding companies. Table 9 shows the Operating/Holding company ratio for all of the companies with outstanding S\&P rated bonds in descending order. With 5.7, Japan has the highest ratio and China has the lowest with 0.2 .

Note that, a holding company financing is a loan made at the holding company level that may be secured by assets or revenues of the subsidiaries and operating companies. Our question 5 scrutinizes the impact of business structure on credit risk and implies that holding company loans might have higher credit risk. Using Table 9, our work suggests that as the Opco/Holdco ratio declines, the overall credit risk of a G20 nation increases.

Table 10, below, provides us with the highest bond ratings of G20 nations together with the S\&P rated total bond count of the country. The table shows, with a few exceptions, that the credit quality is related to the outstanding bonds count and favors the industrialized nations with highly liquid financial markets and many participants (this is relevant for question \#2). However, this should not be confused with the spread comparisons of participating nations for a risk group since Table 10 is not reporting within group risk comparisons. 
Table 9. OPCO-HOLDCO Comparisons with relative ratios in descending order Table prepared using 16 August 2021 data.

\begin{tabular}{cccc}
\hline Country & Opco & Holdco & Opco/Holdco \\
\hline Japan & 263 & 46 & 5.7 \\
Australia & 137 & 35 & 3.9 \\
Canada & 773 & 220 & 3.5 \\
US & 8570 & 2900 & 3.0 \\
UK & 515 & 198 & 2.6 \\
Germany & 342 & 135 & 2.5 \\
Argentina & 24 & 10 & 2.4 \\
Brazil & 63 & 28 & 2.3 \\
Italy & 157 & 84 & 1.9 \\
France & 398 & 250 & 1.6 \\
India & 47 & 36 & 1.3 \\
Mexico & 103 & 50 & 1.3 \\
Russia & 6 & 16 & 1.2 \\
Turkey & 12 & 6 & 0.8 \\
South Africa & 2 & 110 & 0.3 \\
China & 18 & - & 0.2 \\
\hline South Korea & 72 & - & - \\
Indonesia & 5 & & - \\
\hline
\end{tabular}

Table 10. Highest S\&P ranking \& the number of outstanding bonds. (Date: 16 August 2021).

\begin{tabular}{ccc}
\hline Country & Highest Rate & S\&P Rated Number of Bonds \\
\hline US & AAA & 11,470 \\
Australia & AA+ & 172 \\
Canada & AA+ & 993 \\
France & AA & 639 \\
Indonesia & AA & 5 \\
Korea & AA & 72 \\
UK & AA & 713 \\
Japan & AA- & 309 \\
China & A+ & 128 \\
Germany & A+ & 477 \\
Italy & A- & 241 \\
Mexico & A- & 183 \\
India & BBB + & 83 \\
Brazil & BBB & 91 \\
Turkey & BBB- & 28 \\
Russia & BBB- & 11 \\
Argentina & BB + & 34 \\
South Africa & BB- & 8 \\
\hline
\end{tabular}

Table 10 is a snapshot of the bond-quality ceilings in G20 nations. It simply shows the highest credit quality bonds in each G20 nation together with the number of S\&P rated bonds outstanding. The table shows that the US is the only country with an AAA rating, and the second-best rating assigned to other countries is AA+. However, this does not imply the size or value of within risk-class corporate credit spreads.

Table 10 highlights that to compare the same risk group in all 18 nations, we need to go down to BB-, a rating that is available in all 18 nations. Moreover, 6 out of 18 nations do not have any A rated (including $\mathrm{A}-$ ) bonds outstanding.

\section{Discussion and Conclusions}

Given an upsloping yield curve at the present time, all nations have increasing credit spreads with the terms and risk classes. A quick look at Table 8 shows that when we move from left to right and from top to bottom, we observe the increase in credit spreads of all 
G20 nations with no exceptions. As such, our analysis of the option-adjusted spreads is also useful in suggesting the shape of the yield curves for G20 nations. This suggests that no additional action is required due to the possible differences in the shape of the yield curve for the S\&P rated bonds of G20 nations.

This work highlights several hard-to-discover relationships in the credit-risk field on an international scale. For example, we discovered the connection between the yield spread and the economic advancement of the country. Industrialized countries with liquid financial markets have much less credit risk compared to developing countries. Within the same context, a country's outstanding bond count and the average credit risk is positively correlated (see Table 10). This suggests that a nation's outstanding bond count is connected to liquidity and is inversely related to the size of the credit spread. This may be highlighted as an indicator showing the importance of developed bonds markets for the emerging market countries.

As seen in Tables 3-7, the size of the issues is observed as not correlated with anything. This is primarily due to the fact that its size is related to the country's role in the world of finance and has no impact on the quality of the bonds. Tables 3-7 show that the U.S. as the world's biggest financial market dominates in all issue-size levels, less than and equal to $\$ 500$ million, between 500 million to 1 billion, and greater than 1 billion. The U.S. is followed by the counties with bigger financial markets: France, the UK, Germany, Italy, Canada, and Japan. Our simple conclusion puts size as a factor unrelated to the credit risk.

As for the potential impact of business structure on credit risk, this work reports a very interesting discovery: as the ratio of OPCO/HOLDCO declines (implying an increase in the weight of HOLDCO financing in a national economy), the option-adjusted credit yield-spreads increase, making the nation relatively riskier.

This study shows that the size of the spread is not following a regular pattern within and between the risk classes. Understanding relative size differences in option-adjusted spreads is a complex matter and should be the subject of future studies as the theory tells us that the difference may be attributable to market debt, liquidity, and country risk. However, this decomposition itself constitutes a lengthy study and one of the weaknesses of the present work as we limit the scope to G20 nations and focused less on the decomposition of the spreads.

Author Contributions: Both authors contribute to the paper equally. All authors have read and agreed to the published version of the manuscript.

Funding: This research received no external funding. The research is supported by the OMSB Gargano Endowed Professorship Funds.

Institutional Review Board Statement: Not applicable.

Informed Consent Statement: Not applicable.

Data Availability Statement: The data is obtained from Bloomberg on 16 August 2021.

Conflicts of Interest: The authors declare no conflict of interest.

\section{Notes}

1 Default risk is also referred to as credit risk and sometimes confusingly considered as a sub-category or a component of the credit risk, wherein a probability calculated by the lender to quantify the chance of the borrower failing to honor his obligations towards principal and/or towards interest and it is dependent on various factors such as financial health of the borrower, economic factors affecting the business of the borrower, etc. In this work, we will use the term default risk interchangeably with credit risk.

2 The risk-free rate is a theoretical concept and assumes that all possible risk dynamics are removed.

3 As an example, if the expected yield of a 20-year ATT bond is needed, one has to start with the 20-year Treasury bond's yield and add the corporate spread computed for the 20-year ATT bond. However, this spread is not easy to obtain as it requires computing the risks attributable to ATT under a certain set of assumptions.

4 Standard \& Poor's, Moody's, and Fitch are the prominent rating providers. 
$5 \quad$ Financial tools have factors for measurement and quantification but not all factors are quantitative. Accordingly, default risk may be assessed using key factors such as recent losses of the issuer, the financial position of the issuer presented in the latest audited statements, characteristics of the funds, cash flows, and long-term assets flow, the character standing of the borrower, as well as the present macro-economic conditions.

6 The option-adjusted spread is a constant spread added to the prevailing rate to discount the cash flows but OAS uses a number of scenarios carrying possibilities of numerous interest rate paths that are calibrated to the security yield curve. The cash flows are determined along all the paths, and the results are used in arriving at the price of the security. OAS is, hence, model-dependent and, as highlighted by Fabozzi (2006), if the valuation model is poor, the OAS will be meaningless.

7 https://www.g20.org/about-the-g20.html Access on 8 September 2021.

8 Around 2008, the G20 declared itself the primary venue for international economic and financial cooperation, and its stature has risen ever since and is recognized by analysts as exercising considerable global influence but criticized for its limited membership and lack of enforcement powers. Summits are often met with protests, particularly by anti-globalization groups.

9 A portfolio's OAS is taken as the weighted average of the OAS of individual securities where weight is the market price of the securities. This limits the use of OAS to such users who want to inspect the daily contribution to return at present.

10 Notice that if the current market value of $P_{0}=\$ 1018$ is replaced by the par value of $\$ 1000$, solving for $R_{S 2}$ yields 0.02 or 2 percent ( $4 \%$ annualized) implying both spot rates, six-months and one-year are $2 \%$ (4\% annualized) for par bonds as explained by textbooks.

$$
\$ 1000=\frac{\$ 20}{1.02}+\frac{\$ 1020}{1.02^{2}}
$$

\section{References}

Abdul Razak, Lutfi, Mansor H. Ibrahim, and Adam Ng. 2020. Which Sustainability Dimensions Affect Credit Risk? Evidence from Corporate and Country-Level Measures. Journal of Risk and Financial Management 13: 316. [CrossRef]

An, Jaehyung, Alexey Mikhaylov, and Ulf H. Richter. 2020. Trade War Effects: Evidence from Sectors of Energy and Resources in Africa. Heliyon 6: e05693. [CrossRef] [PubMed]

Anderson, Ronald, and Suresh Sundaresan. 1996. Design and Valuation of Debt Contracts. Review of Financial Studies 9: 37-68. [CrossRef]

Anderson, Ronald, and Suresh Sundaresan. 2000. A Comparative Study of Structural Models of Corporate Bond Yields: An Exploratory Investigation. Journal of Banking and Finance 24: 255-69. [CrossRef]

Anderson, Ronald, Suresh Sundaresan, and Pierre Tychon. 1996. Strategic Analysis of Contingent Claims. European Economic Review 40: 871-81. [CrossRef]

Black, Fisher, and Myron Scholes. 1973. The Pricing of Options and Corporate Liabilities. Journal of Political Economy 81: 637-59. [CrossRef]

Cavallo, Eduardo, and Patricio Valenzuela. 2007. The Determinants of Corporate Risk in Emerging Markets: An Option-Adjusted Spread Analysis. IMF Working Paper No. 07/228. Available online: https:/ / ssrn.com/abstract=1033210 (accessed on 8 May 2021.).

Choudhry, Moorad. 2004. Advanced Fixed Income Analysis. Amsterdam: Elsevier Butterworth-Heinemann.

Collin-Dufresne, Pierre, and Robert Goldstein. 2001. Do Credit Spreads Reflect Stationary Leverage Ratios? Journal of Finance 56: 1929-57. [CrossRef]

Collin-Dufresne, Pierre, Robert Goldstein, and Spencer Martin. 2001. The Determinants of Credit Spread Changes. Journal of Finance 56: 2177-208. [CrossRef]

Duffie, Darrell, and David Lando. 2001. Term Structure of Credit Spreads with Incomplete Accounting Information. Econometrica 69: 633-64. [CrossRef]

Elton, Edwin, Martin Gruber, Deepak Agrawal, and Christopher Mann. 1999. Explaining the Rate Spread on Corporate Bonds. NYU Stern School of Business Research Paper Series; Working Paper No. FIN-99-082. New York: NYU Stern School, Available online: https: / / ssrn.com/abstract=1299452 (accessed on 8 January 2021).

Eom, Young-Ho, Jean Helwege, and Jing-Zhi Huang. 2004. Structural Models of Corporate Bond Pricing: An Empirical Analysis. The Review of Financial Studies 17: 499-544. [CrossRef]

Fabozzi, Frank. 2006. Fixed Income Mathematics, 4th ed. London: McGraw Hill.

Huang, Jing-Zhi, and Ming Huang. 2012. How Much of the Corporate-Treasury Yield Spread Is Due to Credit Risk? The Review of Asset Pricing Studies 2: 153-202. [CrossRef]

Jones, Philip, Scott Mason, and Eric Rosenfeld. 1984. Contingent Claims Analysis of Corporate Capital Structures: An Empirical Analysis. Journal of Finance 39: 611-25. [CrossRef]

Leland, Hayne. 1994. Corporate Debt Value, Bond Covenants, and Optimal Capital Structure. Journal of Finance 49: 1213-52. [CrossRef]

Leland, Hayne. 1998. Agency Costs, Risk Management, and Capital Structure. Journal of Finance 53: 1213-42. [CrossRef]

Leland, Hayne, and Klaus Toft. 1996. Optimal Capital Structure, Endogenous Bankruptcy, and the Term Structure of Credit Spreads. Journal of Finance 51: 987-1019. [CrossRef]

Lin, Hai, Xinyuan Tao, Junbo Wang, and Chunchi Wu. 2020. Credit Spreads, Business Conditions, and Expected Corporate Bond Returns. Journal of Risk and Financial Management 13: 2-20. [CrossRef] 
Longstaff, Francis, and Eduardo Schwartz. 1995. Valuing Risky Debt: A New Approach. Journal of Finance 3: 789-820. [CrossRef]

Lyden, Scott, and David Saraniti. 2000. An Empirical Examination of the Classical Theory of Corporate Security Valuation. Available online: https:/ / papers.ssrn.com/sol3/papers.cfm?abstract_id=271719 (accessed on 8 January 2021).

Mella-Barral, Pierre, and William Perraudin. 1997. Strategic Debt Service. Journal of Finance 52: 531-66. [CrossRef]

Merton, Robert. 1974. On the Pricing of Corporate Debt: The Risk Structure of Interest Rates. Journal of Finance 29: 449-70.

Mutalimov, Verdi, Irina Kovaleva, Alexey Mikhaylov, and Diana Stepanova. 2021. Assessing the regional growth of small business in Russia. Entrepreneurial Business and Economics Review 9: 119-33. [CrossRef]

Nehrebecka, Natalia. 2021. COVID-19: Stress-testing non-financial companies: A macroprudential perspective. The experience of Poland. Eurasian Econ Review 11: 283-319. [CrossRef]

Rousseau, Stephane. 2009. Regulating Credit Rating Agencies after the Financial Crisis: The Long and Winding Road Toward Accountability. Toronto: Capital Markets Institute Research Paper. [CrossRef]

Smith, Roy, and Ingo Walter. 2002. Rating Agencies: Is There an Agency Issue? In Ratings, Rating Agencies, and the Global Financial System. Edited by Majnoni Levich and Carmen Reinhart. Boston: Kluwer Academic Publishers, pp. $295-97$.

White, Lawrence. 2002. The Credit Rating Industry: An Industrial Organization Analysis. In Ratings, Rating Agencies, and the Global Financial System. Edited by Majnoni Levich and Carmen Reinhart. Boston: Kluwer Academic Publishers, p. 45.

Zhou, Chunsheng. 2001. The Term Structure of Credit Spreads with Jump Risk. Journal of Banking E Finance 25: $2015-40$.

Zhou, Xing. 2020. Corporate Debt. Journal of Risk and Financial Management 13: 199. [CrossRef] 